\title{
Hypoxanthine as a Test of Perinatal Hypoxia as Compared to Lactate, Base Deficit, and pH
}

\author{
STEN SWANSTRÖM AND LARS-ERIC BRATTEBY ${ }^{(18)}$ \\ Perinatal Research Unit of the Department of Pediatrics and the Unit of Pediatric Physiology of the Department of \\ Clinical Physiology, University Hospital, Uppsala, Sweden.
}

\begin{abstract}
Summary
The possibility of detecting past hypoxia during the first $2 \mathrm{~h}$ after birth by means of blood analyses of hypoxanthine, lactate, base deficit, and pH was investigated in six infants with a 1 min Apgar score of $\leq 4$. Reference values for the four biochemical variables were obtained in 16 healthy infants with a normal 1 min Apgar score of $\geq 8$. In the asphyxiated infants, elevated values for hypoxanthine were found in $48 \%$, for lactate in $54 \%$, and for base deficit in $46 \%$ while $21 \%$ of the pH values were lower than the reference. In the group of asphyxiated infants, significantly elevated hypoxanthine values were found during the first $\mathbf{2 0}$ min after birth, base deficit during $30 \mathrm{~min}$, and lactate values during 120 min while lower $\mathrm{pH}$ values than the reference were found during the first $30 \mathrm{~min}$. Significant correlations were found between hypoxanthine and lactate concentrations and also between hypoxanthine and base deficit but not between hypoxanthine and $\mathrm{pH}$. It is concluded that the optimal time for detecting past intrauterine hypoxia in the newborn using the hypoxanthine test is between 10 and $20 \mathrm{~min}$ after birth, but in individual cases, significantly increased hypoxanthine concentrations may be found at any time in the 10-120 min period. We propose an equation that can be used to calculate an upper normal limit for hypoxanthine concentration in any sampling time during this period.
\end{abstract}

\section{Speculation}

The addition of the plasma hypoxanthine concentration to established biochemical tests of perinatal asphyxia such as lactate, base deficit and $\mathrm{pH}$ analyses may improve the possibility of detecting past hypoxia accurately. Differences in appearance time, duration and degree of significant changes in the biochemical tests indicates that the optimal sampling time for the disclosure of past asphyxia differs for different tests.

When the cell lacks oxygen, the production of ATP is dramatically reduced, and ATP is broken down to ADP and AMP and further as far as to hypoxanthine. This metabolite can be used as an indicator of hypoxia in the perinatal period $(7,8)$. A previous paper described the pattern of changes in the hypoxanthine concentration in arterial plasma during the first $2 \mathrm{~h}$ after birth (2). Rapid changes in this concentration occurred in both normal and asphyxiated infants in the early neonatal period and it was noted that marked differences in the plasma hypoxanthine level between these two groups of infants are best revealed by repeated blood samples.

The present study was undertaken to examine the reliability of the hypoxanthine test and to ascertain how long after birth it could be used to discriminate asphyxiated infants from a control group presented earlier (2). A comparison was also made between the discriminating capacity of hypoxanthine in detecting past hypoxia and that of base deficit, lactate, and $\mathrm{pH}$.

\section{MATERIALS AND METHODS}

Hypoxanthine. Hypoxanthine analyses were performed by the method of Saugstad, with his original equipment as described in an earlier paper (2). The error of a single measurement was 1.8 mmole/liter, in accordance with Saugstad's findings (7).

Arterial blood gases and acid base. Blood gases were determined in IL 313 Instrumentation Laboratory equipment. Analyses were made in duplicate and the analytical error for $\mathrm{pH}$ was $\pm 1 \%$, for $\mathrm{PaO}_{2} \pm 2.2 \%$, and for $\mathrm{PaCO}_{2} \pm 3.2 \%$. Base deficit values were obtained from the Siggaard-Andersen Alignment nomogram (9) from $\mathrm{PCO}_{2}$ and $\mathrm{pH}$ and were calculated for extracellular fluid, that is at $\mathrm{Hb} 50 \mathrm{~g} /$ liter as advised by Rooth and Jacobson (6), thus avoiding the influences of $\mathrm{PCO}_{2}$ and haemoglobin values on the estimations of metabolic acidosis.

Lactate. Immediately after sampling, blood was mixed with icecold metaphosphoric acid. These assays were performed by the enzymatic method of Marbach and Weil (5). The analytical error for lactate was $\pm 2.3 \%$.

Subjects. The subjects comprising the reference group and the clinical procedures have been presented earlier (2). The subjects were investigated as part of another study (10). All infants had a normal Apgar score $(\geq 8)$ and were full-term with weight and length appropriate for their gestational age. Blood samples were obtained at $10,20,30,60,80$, and 120 min of age through an umbilical arterial catheter. Blood gases in the first $2 \mathrm{~h}$ after birth did not indicate any delayed respiratory adaptation, the $\mathrm{PaO}_{2}$ and $\mathrm{PaCO}_{2}$ being in accordance with reference values from the literature (11).

To be assigned to the asphyxia group, the infants should have a 1 min Apgar score $\leq 6$. As it turned out, all six infants in this group were clinically severely asphyxiated, with 1 min Apgar scores $\leq 4$ and $5 \mathrm{~min}$ scores $\leq 7$. The case histories of cases 1-3, 5 , 6 , and case A have been described earlier (2). Case 4 is described below. Clinical data for the asphyxiated infants are summarized in Table 1.

Case A did not comply with the criteria used for selecting infants for the reference group, as this child was born in the breech position, nor did it fit the criterion for the asphyxia group, as the 1 min Apgar score was 9. He was included in the study because of biochemical signs of asphyxia. In the presentation of results, however, values from this infant are used only for the correlations between different variables presented in Table 2 .

In case 4 the Apgar score was 3 at $1 \mathrm{~min}$ and 7 at $5 \mathrm{~min}$. The birth weight was $3700 \mathrm{~g}$ and gestational age $41 \mathrm{wk}$. This infant was delivered by Caesarean section because of protracted labour with a face presentation. It was observed that the placenta constituted a mechanical obstruction.

Immediate resuscitative measures were taken in the six clinically asphyxiated infants and all blood gases indicated that the asphyxia was successfully treated with no relapsing episode of hypoxia $\left(\mathrm{PaO}_{2} \leq 6.7 \mathrm{kPa}\right)$, or carbon dioxide retention $\left(\mathrm{PaCO}_{2} \geq 6.7 \mathrm{kPa}\right)$. The blood gases in case $\mathrm{A}$ were also within these limits. For practical and clinical reasons lactate determinations were not 
Table 1. Clinical data in the asphyxia group

\begin{tabular}{|c|c|c|c|c|c|}
\hline \multirow[b]{2}{*}{ Case } & \multirow[b]{2}{*}{ Asphyxiated infants } & \multirow{2}{*}{$\begin{array}{c}\text { Birth } \\
\text { weight } \\
\text { (g) }\end{array}$} & \multirow{2}{*}{$\begin{array}{c}\text { Gesta- } \\
\text { tional } \\
\text { age } \\
\text { (wk) }\end{array}$} & \multicolumn{2}{|c|}{ Apgar score } \\
\hline & & & & $\begin{array}{c}1 \\
\min \end{array}$ & $\begin{array}{c}5 \\
\min \end{array}$ \\
\hline 1 & $\begin{array}{l}\text { Fetal bradycardia, emer- } \\
\text { gency Caesarean section }\end{array}$ & 3160 & 40 & 2 & 2 \\
\hline 2 & Breech delivery & 3220 & 43 & 1 & 4 \\
\hline 3 & $\begin{array}{l}\text { Fetal bradycardia, passage } \\
\text { of meconium }\end{array}$ & 3200 & 43 & 3 & 6 \\
\hline 4 & $\begin{array}{l}\text { Fetal bradycardia, anoma- } \\
\text { lous presentation }\end{array}$ & 3700 & 41 & 3 & 7 \\
\hline 5 & $\begin{array}{l}\text { Prolapsed extremity, emer- } \\
\text { gency Caesarean section }\end{array}$ & 2830 & 36 & 4 & 7 \\
\hline 6 & $\begin{array}{l}\text { Fetal bradycardia, meco- } \\
\text { nium passage }\end{array}$ & 3000 & 42 & 4 & 7 \\
\hline A & Breech delivery & 3170 & 38 & 9 & 9 \\
\hline
\end{tabular}

Table 2. Correlation between different variables indicating hypoxia in asphyxiated and in nonasphyxiated infants. $B D=$ base deficit

\begin{tabular}{|c|c|c|c|c|c|c|}
\hline \multirow[b]{2}{*}{ Correlation } & \multicolumn{6}{|c|}{ Sampling time, min after birth } \\
\hline & 10 & 20 & 30 & 60 & 90 & 120 \\
\hline \multicolumn{7}{|l|}{$\begin{array}{l}\text { Hypoxanthine/ } \\
\text { lactate }\end{array}$} \\
\hline $\mathrm{r}$ & 0.68 & 0.75 & 0.48 & 0.56 & 0.56 & 0.22 \\
\hline$n$ & 15 & 11 & 17 & 14 & 16 & 12 \\
\hline$P<$ & 0.01 & 0.01 & 0.05 & 0.05 & 0.02 & n.s. ${ }^{1}$ \\
\hline \multicolumn{7}{|l|}{$\begin{array}{l}\text { Hypoxanthine/ } \\
\text { BD }\end{array}$} \\
\hline $\mathbf{r}$ & 0.72 & 0.63 & 0.54 & 0.48 & 0.40 & 0.39 \\
\hline$n$ & 15 & 13 & 18 & 14 & 16 & 12 \\
\hline$P<$ & 0.001 & 0.02 & 0.05 & n.s. & n.s. & n.s. \\
\hline \multicolumn{7}{|c|}{ Hypoxanthine/pH } \\
\hline $\mathrm{r}$ & -0.43 & 0.13 & -0.43 & 0.04 & -0.13 & 0.24 \\
\hline$n$ & 15 & 13 & 19 & 14 & 16 & 12 \\
\hline$P<$ & n.s. & n.s. & n.s. & n.s. & n.s. & n.s. \\
\hline \multicolumn{7}{|l|}{ Lactate/BD } \\
\hline $\mathbf{r}$ & 0.86 & 0.88 & 0.77 & 0.66 & 0.70 & 0.56 \\
\hline$n$ & 17 & 16 & 20 & 20 & 20 & 20 \\
\hline$P<$ & 0.001 & 0.001 & 0.001 & 0.001 & 0.001 & 0.01 \\
\hline \multicolumn{7}{|l|}{ Lactate/pH } \\
\hline $\mathbf{r}$ & -0.60 & -0.39 & -0.41 & -0.30 & -0.29 & -0.10 \\
\hline$n$ & 17 & 16 & 20 & 20 & 20 & 20 \\
\hline$P<$ & 0.01 & n.s. & n.s. & n.s. & n.s. & n.s. \\
\hline \multicolumn{7}{|l|}{$\mathrm{BD} / \mathrm{pH}$} \\
\hline $\mathbf{r}$ & -.74 & -0.55 & -0.63 & -0.68 & -0.73 & -0.34 \\
\hline$n$ & 17 & 20 & 21 & 20 & 20 & 20 \\
\hline$P<$ & 0.001 & 0.01 & 0.01 & 0.001 & 0.001 & n.s. \\
\hline
\end{tabular}

made in Cases 1 and 5 and some sampling times differed from those of the reference group (Table 3 ).

\section{RESULTS}

Mean values for hypoxanthine concentration, base deficit, lactate, and $\mathrm{pH} \pm 1 \mathrm{~S} . \mathrm{D}$. at different sampling times in the reference group are presented in Table 4 . In Table 3 the individual values of these variables are given for the six asphyxiated infants (cases $1-6)$ and case A.

As compared with the reference group (Student's unpaired $t$ test), significantly higher mean values were found for hypoxanthine concentration, base deficit, and blood lactate and significantly lower mean values for blood $\mathrm{pH}$ in the asphyxia group. The levels of significance for the differences at various sampling times are given in Figure 1. Whereas the mean hypoxanthine values differed significantly from those of the reference group only at 10 and $20 \mathrm{~min}$ of age, base deficit and $\mathrm{pH}$ values were still significantly different $30 \mathrm{~min}$, and lactate values $120 \mathrm{~min}$ after birth.

When the asphyxia group and the reference group were combined, a significant correlation $(r=0.86, n=17, P<0.01)$ was found between the sum of the Apgar scores at 1 and 5 min of age and the hypoxanthine concentrations at $10 \mathrm{~min}$ of age. At $20 \mathrm{~min}$ of age there was only a tendency to such a relationship $(r=0.57$, $n=17, P<0.05$ )

In order to examine the possibility of disclosing past hypoxia from single blood samples in the asphyxiated infants, all values noted in this group were related to the corresponding mean values of the reference group at equivalent sampling times. Any value of hypoxanthine, base deficit, or lactate above the reference mean +2 S.D. or any $\mathrm{pH}$ value below the reference mean -2 S.D. was regarded as indicating past hypoxia. Over the whole sampling period the fraction of such discriminating samples in the asphyxia group was 14/29 for hypoxanthine, 13/28 for base deficit, 12/22 for lactate and $6 / 28$ for $\mathrm{pH}$ (Table 3 ). In the reference group the corresponding fractions were $4 / 81$ for hypoxanthine, $2 / 88$ for base

Table 3. Base deficit, $p H$ and blood concentrations of hypoxanthine and lactate in the asphyxiated infants at different sampling times

\begin{tabular}{|c|c|c|c|c|c|}
\hline Case & $\begin{array}{l}\text { Sampling } \\
\text { time } \\
\text { (min after } \\
\text { birth) }\end{array}$ & $\begin{array}{c}\text { Hypoxan- } \\
\text { thine } \\
(\mu \mathrm{mole} / \text { liter })\end{array}$ & $\begin{array}{c}\text { Lactate } \\
\text { (mmole/li- } \\
\text { ter) }\end{array}$ & $\begin{array}{c}\text { Base deficit } \\
\text { (mmole/li- } \\
\text { ter) }\end{array}$ & $\mathrm{pH}$ \\
\hline \multirow[t]{4}{*}{1} & 14 & 48.3 & & & \\
\hline & 17 & 39.9 & & 16 & 7.27 \\
\hline & 30 & 17.5 & & & \\
\hline & 45 & & & 16 & 7.30 \\
\hline \multirow[t]{6}{*}{2} & 11 & 37.8 & 11.5 & 17 & 7.11 \\
\hline & 20 & 16.1 & 11.2 & 18 & 7.23 \\
\hline & 30 & 20.3 & 10.8 & 16 & 7.27 \\
\hline & 60 & 11.9 & 9.4 & 15 & 7.32 \\
\hline & 90 & 9.8 & 9.1 & 14 & 7.34 \\
\hline & 120 & 4.9 & 7.0 & 10 & 7.36 \\
\hline \multirow[t]{6}{*}{3} & 17 & 18.2 & 6.5 & 10 & 7.30 \\
\hline & 20 & 10.5 & 6.6 & 11 & 7.31 \\
\hline & 30 & 5.6 & 6.5 & 11 & 7.37 \\
\hline & 60 & 16.6 & 4.4 & 10 & 7.45 \\
\hline & 90 & 9.1 & 3.6 & 9 & 7.42 \\
\hline & 120 & 18.9 & 3.5 & 10 & 7.43 \\
\hline \multirow[t]{5}{*}{4} & 20 & 1.4 & 5.3 & 6 & 7.31 \\
\hline & 30 & 0 & 4.2 & 5 & 7.37 \\
\hline & 60 & 0 & 2.3 & 0 & 7.40 \\
\hline & 90 & 0 & 1.6 & 1 & 7.40 \\
\hline & 120 & 1.4 & 1.5 & 1 & 7.38 \\
\hline \multirow[t]{5}{*}{5} & 11 & 36.0 & & 13 & 7.23 \\
\hline & 17 & 23.8 & & 11 & 7.17 \\
\hline & 22 & 33.6 & & 3 & 7.37 \\
\hline & 27 & 19.6 & & 9 & 7.35 \\
\hline & 47 & & & & \\
\hline \multirow[t]{5}{*}{6} & 28 & 7 & 6.5 & 10 & 7.33 \\
\hline & 30 & 4.9 & 6.4 & 11 & 7.37 \\
\hline & 60 & 1.4 & 4.8 & 10 & 7.39 \\
\hline & 90 & 0.7 & 3.2 & 8 & 7.40 \\
\hline & 120 & 0 & 2.6 & 6 & 7.38 \\
\hline \multirow[t]{7}{*}{ Case A } & 9 & 18.9 & 8.8 & 16 & 7.09 \\
\hline & 10 & 22.4 & 10.5 & 16 & 7.13 \\
\hline & 20 & 28.0 & 7.5 & 17 & 7.24 \\
\hline & 30 & 5.6 & 7.0 & 12 & 7.39 \\
\hline & 60 & 0 & 3.5 & 15 & 7.29 \\
\hline & 90 & 9.8 & 3.6 & 16 & 7.24 \\
\hline & 120 & 7.0 & 7.0 & 14 & 7.33 \\
\hline
\end{tabular}


Table 4. Base deficit, $p H$ and blood concentrations of hypoxanthine and lactate in the reference group at different sampling times

\begin{tabular}{|c|c|c|c|c|c|c|}
\hline & \multicolumn{6}{|c|}{ Sampling time, $\min$ after birth } \\
\hline & 10 & 20 & 30 & 60 & 90 & 120 \\
\hline \multicolumn{7}{|c|}{$\begin{array}{l}\text { Hypoxanthine, } \mu \text { mole/ } \\
\text { liter }\end{array}$} \\
\hline Mean & 12.2 & 7.7 & 7.8 & 3.8 & 3.4 & 1.3 \\
\hline \pm 1 S.D. & 7.2 & 5.9 & 5.1 & 3.7 & 2.5 & 1.2 \\
\hline$n$ & 14 & 12 & 15 & 14 & 15 & 12 \\
\hline \multicolumn{7}{|c|}{ Lactate, mmole/liter } \\
\hline Mean & 4.6 & 4.2 & 3.6 & 2.5 & 2.3 & 2.1 \\
\hline \pm 1 S.D. & 1.6 & 1.5 & 1.3 & 0.8 & 0.8 & 0.7 \\
\hline$n$ & 15 & 13 & 15 & 15 & 15 & 15 \\
\hline \multicolumn{7}{|c|}{$\begin{array}{l}\text { Base deficit }{ }_{\mathrm{ECF}} \text {, mmole/ } \\
\text { liter }\end{array}$} \\
\hline Mean & 7.4 & 8.3 & 7.0 & 6.0 & 5.9 & 5.9 \\
\hline \pm 1 S.D. & 2.3 & 2.0 & 2.5 & 1.7 & 2.3 & 2.0 \\
\hline$n$ & 15 & 14 & 15 & 15 & 15 & 15 \\
\hline \multicolumn{7}{|l|}{$\mathrm{pH}$} \\
\hline Mean & 7.28 & 7.33 & 7.38 & 7.41 & 7.40 & 7.40 \\
\hline \pm 1 S.D. & 0.05 & 0.04 & 0.03 & 0.04 & 0.04 & 0.03 \\
\hline$n$ & 15 & 14 & 15 & 15 & 15 & 15 \\
\hline
\end{tabular}

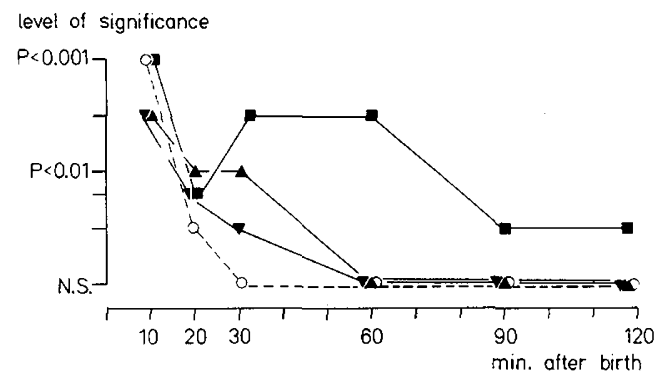

Fig. 1. Level of significant increase in hypoxanthine $\left(\mathrm{O}_{-}-\mathrm{O}\right)$, lactate (- base deficit $(\boldsymbol{\Lambda}-\mathbf{\Lambda})$ and decrease in $\mathrm{pH}(\boldsymbol{\nabla}-\mathbf{\nabla})$ in the asphyxia group as compared with the reference group at different sampling times. Hypoxanthine values differed for $20 \mathrm{~min}, \mathrm{pH}$ and base deficit for $30 \mathrm{~min}$ and lactate for $120 \mathrm{~min}$.

deficit, $3 / 86$ for lactate and $4 / 88$ for $\mathrm{pH}$. The result in the latter group is of course due to the statistical limit used.

It was noted empirically that in the reference group the mean hypoxanthine values at the various sampling times best fitted a regression line $\mathrm{Y}=107.8 \mathrm{X}+2.1(r=0.95, P<0.001)$, where $\mathrm{Y}$ $=$ the mean reference values of hypoxanthine and $X=$ the sampling times ${ }^{-1}$ (Equation 1), Figure 2 . In order to obtain values that could be used as an upper normal hypoxanthine limit at any sampling time between 10 and 120 min of age, a new regression line was drawn, based on the mean values +2 S.D., namely $\mathrm{Y}=$ $222.9 \mathrm{X}+6.4$ (Equation 2). The corresponding hyperbolas are presented in Figure 3 together with all hypoxanthine values noted in the asphyxia group and in case A.

The extent to which the mean values for the four different variables in every sample obtained in the asphyxiated infants deviated from the mean reference values is shown in Figures $4 a$ and $4 b$. The deviation from the reference mean is expressed as the standard deviation from this mean. Hypoxanthine was the strongest discriminator in cases 1,3 and 5 , with values increased $6.0,4.8$, and 5.5 S.D. above the reference mean values at 14,120 , and 22 min of age, respectively. Lactate was the strongest discriminator in infants 2 and 6, with increases by 9.0 and 2.8 S.D. at 90 and 60 min, respectively. It is worthy of note that in infant No. 4, all variables indicated less hypoxia than in the reference group at most sampling times.

When all infants in the reference group, cases 1-6 of the asphyxia group, and case A were combined, and all variables were correlated with each other at the different sampling times (Table

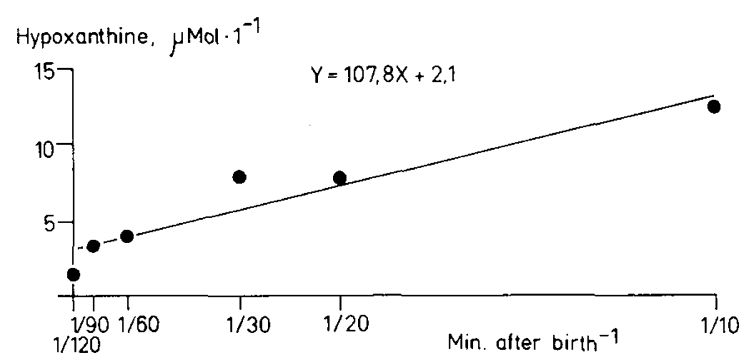

Fig. 2. Correlation between mean hypoxanthine concentration and sampling time $\mathrm{e}^{-1}$ after birth.

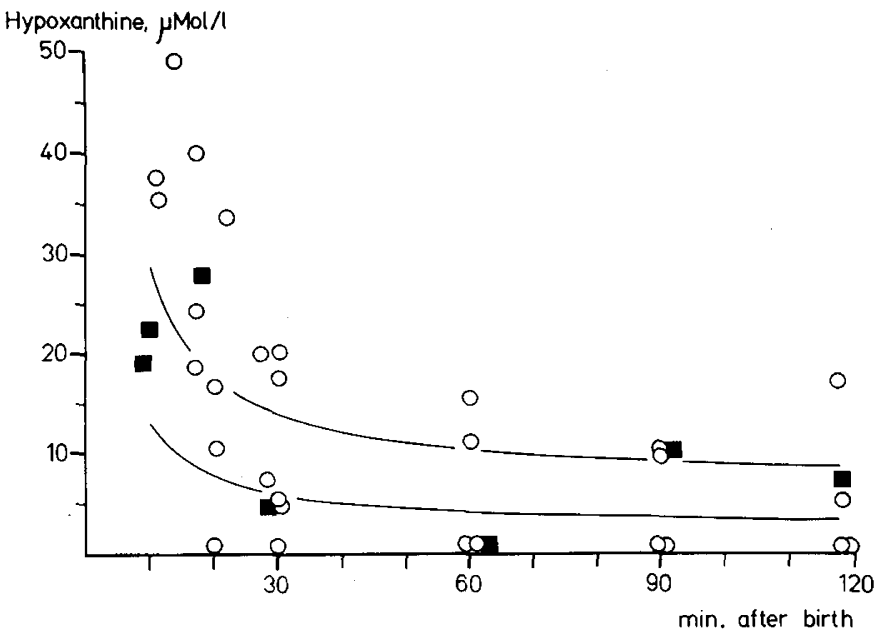

Fig. 3. Plasma concentrations of hypoxanthine in clinically asphyxiated infants, cases $1-6(O)$, and in an infant, case A (D), with metabolic acidosis indicating past hypoxia. Reference mean values are represented by the hyperbola $\mathrm{I}\left(\mathrm{Y}=107.8 \mathrm{x}\right.$ sampling time $\left.\mathrm{e}^{-1}+2.1\right)$. Reference mean values +2 S.D. are represented by the hyperbola II $\left(\mathrm{Y}=222.9 \times\right.$ sampling time $^{-1}$ $+6.4)$.

4) hypoxanthine showed a significant correlation with lactate and base deficit at 10 and 20 min of age, but at no sampling time with $\mathrm{pH}$. A tendency to a positive correlation with base deficit up to 30 min and with lactate up to $90 \mathrm{~min}$ of age was observed.

\section{DISCUSSION}

If past hypoxia is to be detected in newborn infants by means of hypoxanthine analyses, it is of obvious importance to have appropriate reference values. The difficulty in defining such standard values lies in the fact that even uncomplicated deliveries are accompanied to a certain extent by some degree of hypoxia, as indicated by an increased metabolic acidosis early after birth even though the Apgar score is normal (14). Consequently, hypoxanthine should also be expected to show some increase after birth in all infants. When excessive hypoxia occurs, the hypoxanthine values noted must be compared with "normally" increased levels of hypoxanthine, just as in the case when lactate or base deficit is used for detection of past hypoxia (1).

In the reference group all infants were judged to have sustained no more and no less hypoxia during their deliveries than could normally be expected. Their 1 min Apgar scores were $\geq 8$ and their base deficit, lactate, and $\mathrm{pH}$ values after birth (Table 4) corresponded to reference values reported in the literature $(1,11)$. Furthermore, analyses of $\mathrm{PaO}_{2}$ and $\mathrm{PaCO}_{2}$ from 10 to 120 min after birth indicated a normal gas exchange during the sampling period. These findings supported our concept that the postnatal hypoxanthine concentrations noted in our reference group were representative for healthy full-term infants with uncomplicated deliveries.

The asphyxia group was selected only on the basis of low Apgar scores, which is an established clinical way of identifying asphyxiated infants. It should be remembered, however, that the 


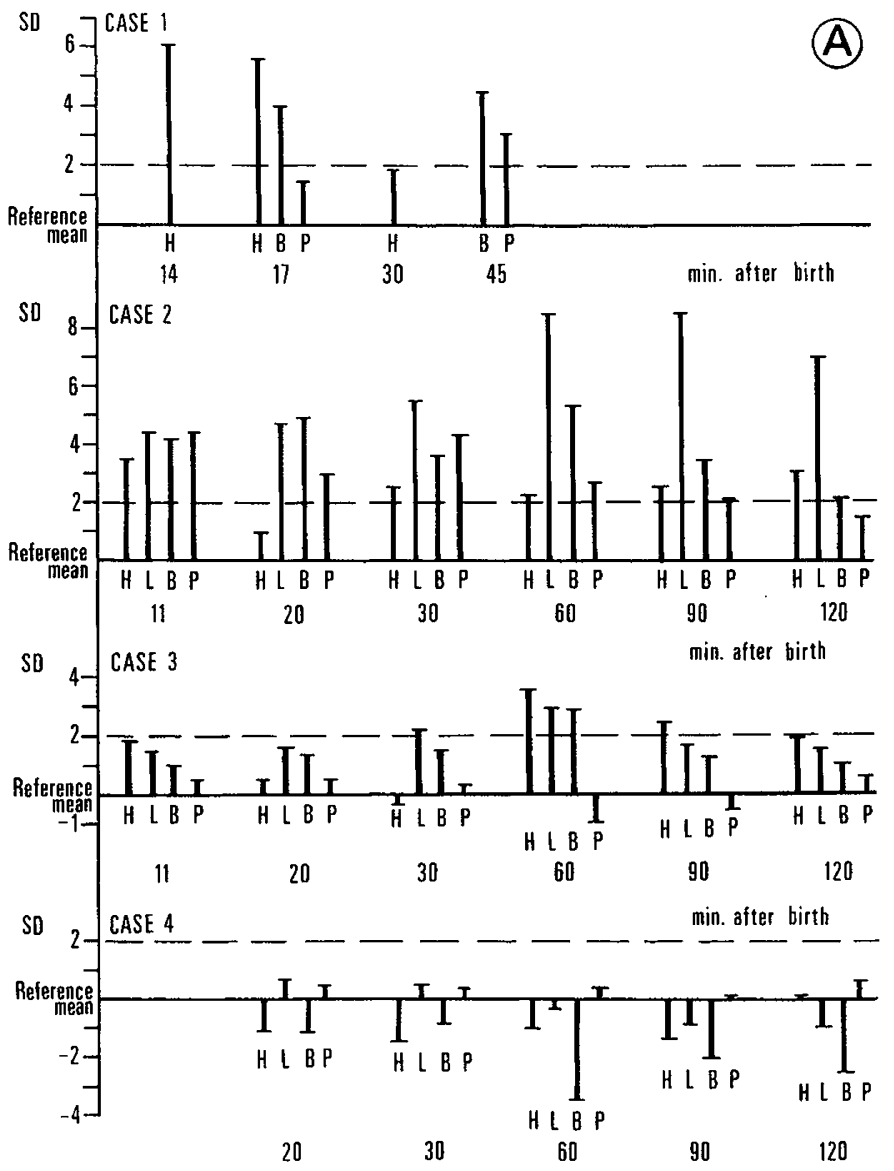

min. after birth

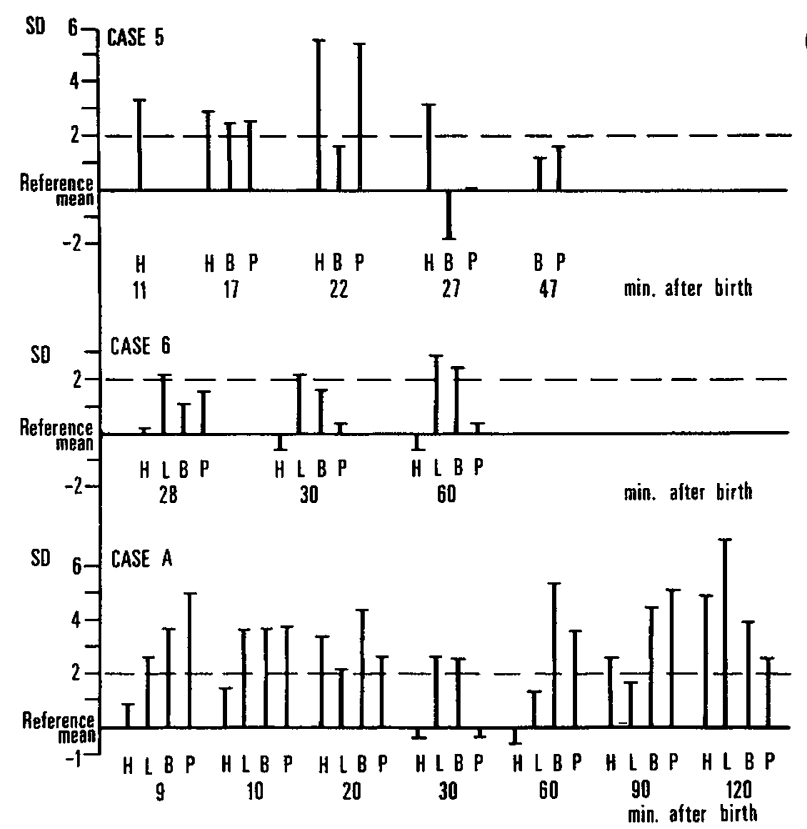

Fig. $4 a$ and $b$. Base deficit (B), hydrogen ion activity (P) and blood concentrations of hypoxanthine $(\mathrm{H})$ and lactate $(\mathrm{L})$ in the asphyxiated infants (cases 1-6) and in an infant with metabolic acidosis (case A) related to the corresponding mean values of the reference group. The deviation from the reference mean is expressed as standard deviation from this mean.

Apgar score is not specific for hypoxia. If the hypoxic event occurred sometime before birth, it is quite possible for an asphyxiated infant to be born with a normal Apgar score (1). Infants with a low Apgar score may also be depressed for other reasons than hypoxia. From the biochemical point of view, it may be suspected that case 4 of the asphyxia group, if any, sustained less hypoxia than the infants in the reference group, in spite of a low Apgar score. The metabolic acidosis in this infant was significantly less pronounced than that in the reference group from 60 to 120 min of age (Fig. $4 a$ ).

If, for this reason, case 4 is removed from the asphyxia group, the fractions of values indicating hypoxia, i.e., values increased by more than 2 S.D. above the reference mean, will increase for all the biochemical tests of hypoxia used. For hypoxanthine it will be $14 / 25(58 \%)$, for lactate $12 / 17(71 \%)$, for base deficit $16 / 23(52 \%)$ and for $\mathrm{pH} 6 / 25(24 \%)$. When the mean hypoxanthine values in the remaining five asphyxiated infants with low Apgar scores are then compared with those in the reference group, significant differences $(P<0.001)$ are found both at 10 and $20 \mathrm{~min}$ of age, but not at subsequent sampling time while base deficit and lactate discriminate between the 2 groups significantly from 10 to 120 min.

Obviously hypoxanthine values, just as $\mathrm{pH}$ values, are best suited for disclosing past hypoxia in the immediate neonatal period, while lactate and base deficit are more lasting discriminating variables. An explanation for this is that hypoxanthine, being an uncharged metabolite, quickly crosses the membranes along its diffusion gradient and then, when oxygenation is restored after resuscitation, reaches a peak and is eliminated fairly rapidly (2). The $\mathrm{pH}$ values are quickly normalized after the onset of respiration with the elimination of carbon dioxide. Lactate and base deficit, on the other hand, are closely interrelated. Lactate is a charged metabolite that does not pass through membranes so easily, which may explain its prolonged discriminating power.

The optimal time for disclosing past hypoxia with the hypoxanthine test thus seems to be in the 10 to $20 \mathrm{~min}$ period, when the concentrations are best related both to biochemical signs such as base deficit or lactate (Table 4) and to clinical signs such as Apgar scores. In individual cases, however, it may also be of use after this period, as indicated by the fact that nine out of 14 hypoxanthine values in the asphyxia group were increased by more than 2 S.D. above the reference mean after $20 \mathrm{~min}$ of age. The sampling times closest to the asphyxic event were not necessarily best for disclosing past hypoxia. Thus, in case 3 , only la:tate was increased by more than 2 S.D. above the reference mean ir. the first 30 min. Hypoxanthine, lactate, and base deficit all showed such increases at $60 \mathrm{~min}$ of age (Fig. $3 a$ ). A progressively incr asing deviation from reference values with time can be seen for lactate in case 2 . The time when asphyxia is best disclosed in any individual case depends upon several factors, as discussed in a previous paper (2).

Considering the rapid changes observed in the hypoxanthine concentration both in the asphyxiated infants and in the reference group during the first $20 \mathrm{~min}$ of life, it seems important that any value obtained in asphyxiated infants during this period be related to a reference value valid for an equivalent sampling time. In clinical work it is seldom possible to wait for any specific sampling time for which known reference values are available. By means of the two equations presented in the results, reference values for any point of time between 10 and $120 \mathrm{~min}$ of age, based on all samples analysed for hypoxanthine in the reference group, can be obtained (Fig. 3). All values in the asphyxia group were equally well discriminated by equation 2 as by the 2 S.D. limit calculated from samples obtained at one specific sampling time. It should be noted that no reference values can be calculated from this equation for the time period earlier than $10 \mathrm{~min}$ after birth.

In a recent paper, Tuchschmid et al. (13) found no elevation in plasma hypoxanthine concentration in high altitude induced hypoxia in healthy adults while the blood lactate was slightly increased and a ST-T depression was found in the ECG. These authors speculated that the increased plasma hypoxanthine concentration in newborns after delivery may result from other factors, additional to hypoxia. Most probably, however, their own hypoxicemic subjects exposed to simulated high altitude were not hypoxic and one might assume that the indicators of hypoxia as used by these authors were unspecifically positive due to increased sympathetic tone and/or hyperventilation induced by the test 
situation in the low pressure chamber. The ST-T changes as described by Tuchschmid et al. (13) are not specific to myocardial hypoxia, but are most often interpreted as sympaticotonic or functional (3). At a simulated altitude of $6000 \mathrm{~m}$ the $\mathrm{PaO}_{2}$ of the subjects was $35-30 \mathrm{~mm} \mathrm{Hg}$. They hyperventilated which may, in turn, lead to lactic acidosis without the presence of hypoxia. When, in such a situation, the respiratory alcalosis is prevented by carbon dioxide breathing in animals or human volunteers the blood lactate will not increase until arterial oxygen pressure falls below 30 torr (4) indicating the presence of nonhypoxia above this level of $\mathrm{PaO}_{2}$.

In an experimental study on lamb fetuses, Thieringer et al. (12) recently found increased plasma hypoxanthine concentrations during periods of oxygen debt and highly significant correlations between hypoxanthine and other hypoxia variables as $\mathrm{pH}$, base excess, lactate, $\mathrm{PaO}_{2}$ and $\mathrm{PaCO}_{2}$ which appears to corroborate the conclusion that plasma hypoxanthine concentration reflects tissue hypoxia in the fetal lamb.

To detect and quantify past hypoxia clinically in the newborn infant is much more complicated than doing so in an animal experiment. Based on earlier knowledge and experience from the present study we may conclude that there is no ideal measure of neonatal hypoxia available for clinical practice. In the present study the hypoxanthine test was as valid as lactate and base deficit in disclosing past hypoxia. The optimal time after birth in doing so was different for the different biochemical variables. One main conclusion is that the hypoxanthine test may improve the possibilities of disclosing past hypoxia accurately in the newborn infant and that the most likely time period in which hypoxanthine will reveal past hypoxia is the first $10-20 \mathrm{~min}$ after birth.

\section{REFERENCES AND NOTES}

1. Bratteby, L.-E., and Swanström, S.: Arterial lactate and pyruvate concentration in the normal and asphyxiated newborn infant. In: $\mathrm{H}$. Bossart and C. Perret: Lactate in acute conditons. pp. 56-68. (International Symposium on Lactate in Acute Conditions Basel 1978. S. Karger, Basel, 1979.)

2. Bratteby, L.-E., and Swanström, S.: Hypoxanthine concentration in plasma during the first two hours after birth in normal and asphyxiated infants. Pediatr. Res. 16: 152 (1982).

3. Furberg, C.: Effects of beta-adrenergic blockade in ECG, physical working capacity and central circulation with special reference to autonomic imbalance. Acta Med. Scand. suppl., 488: 17 (1968).

4. Harken, A. H.: Lactic acidosis. Surg. Gynec. Obstet., 142: 593 (1976).

5. Marbach, E. P., and Weil, M. H.: Rapid enzymatic measurement of blood lactate and pyruvate. Use and significance of metaphosphoric acid as a common precipitant. Clin. Chem., 13: 314 (1967).

6. Rooth, G., and Jacobson, L.: The value and validity of base excess $e_{e c}$ in perinatal acid-base studies. Scand. J. Clin. Lab. Invest., 28: 283 (1971).

7. Saugstad, O. D.: Hypoxanthine as a measurement of hypoxia. Pediatr. Res., 9: 158 (1975).

8. Saugstad, O. D.: The determination of hypoxanthine and xanthine with a $\mathrm{PO}_{2}$ electrode. Pediatr. Res., 9: 575 (1975).

9. Siggaard-Andersen, O.: Scales for $\mathrm{pH}, \mathrm{PCO}_{2}$, base excess of whole blood of different hemoglobin concentrations, plasma bicarbonate, and plasma total$\mathrm{CO}_{2}$. Scand. J. Clin. Lab. Invest., 15: 211 (1963).

10. Swanström, S., and Bratteby, L.-E.: Metabolic effects of obstetric regional analgesia and of asphyxia in the newborn infant during the first two hours after birth. I. Arterial blood concentrations of glucose. Acta Paediatr. Scand., 70: 791 (1981).

11. Swanström, S., and Bratteby, L.-E.: Metabolic effects of obstetric regional analgesia and of asphyxia in the newborn infant during the first two hours after birth. III. Adjustment of arterial blood gases and acid-base balance. Acta Paediatr. Scand., 70: 811 (1981).

12. Theiringer, K., Saugstad, O. D., and Kjellmer, I.: Plasma hypoxanthine in exteriorized, acutely asphyxiated fetal lambs. Pediatr. Res., 14: 905 (1980).

13. Tuchschmid, P. E., Boutellier, V., Koller, E. A., and Duc, G. V.: Comparison of hypoxanthine, lactate and ECG signs as indicators of hypoxia. Pediatr. Res., 15: 28 (1981).

14. Tunell, R.: The influence of different environmental temperatures on pulmonary gas exchange and blood gas changes after birth. Acta Paediatr. Scand., 64: 57 (1975).

15. The parents were thoroughly informed about this investigation on the infants and gave their full consent to participation. The study was approved by the Ethical Committee of the Faculty of Medicine of Uppsala University.

16. The authors thank the staff of the Department of Obstetrics and Gynecology of the University Hospital of Uppsala for their support and professor Gösta Rooth for reviewing the manuscript.

17. This research was supported by grants from the Bank of Sweden Tercentenary Foundation.

18. Requests for reprints should be addressed to: Dr. Lars-Eric Bratteby, Unit of Pediatric Physiology, University Hospital, S-750 14 Uppsala, Sweden.

19. Received for publication April 13, 1981.

20. Accepted for publication July 13, 1981 